Exceptionality and practice 1

Running head: CALENDRICAL SAVANTS

Calendrical savants: Exceptionality and Practice

Richard Cowan and Daniel P. J. Carney

Institute of Education University of London

2989 words 


\begin{abstract}
The exceptionality of the skills of calendrical savants and the role of practice were investigated. Experiment 1 compared four autistic calendrical savants to Professor Conway, a distinguished mathematician with calendrical skills. Professor Conway answered questions over a greater range of years but some savants knew more calendrical regularities. Experiment 2 studied the development of a calendrical savant's ability to answer date questions for very remote future years. He started by making written calculations and progressed to mental calculation. His variation in response time for remote dates was similar to that for near dates. The findings are consistent with the view that calendrical savants develop their skills through practice.
\end{abstract}

Keywords: Savant; autism; practice; intelligence 


\section{Calendrical savants: Exceptionality and Practice}

Calendrical calculation is the unusual skill of identifying weekdays corresponding to past and future dates. Calendrical savants are people with this skill in conjunction with pervasive developmental disorders or severe intellectual impairments. This paper compares calendrical savants to a mathematician and investigates a calendrical savant's improvement with practice.

Some propose calendrical savants develop their ability by memorizing calendars (Hill, 1978; Young \& Nettelbeck, 1994). This cannot explain savants who can answer date questions outside the range of calendars or make consistent errors outside current and recent centuries (Cowan, O'Connor, \& Samella, 2003; O'Connor, Cowan, \& Samella, 2000).

Another proposal is that they have internalized a published formula for calculating weekdays for dates. This seems unlikely. Executing the formula requires an ability to do division that is beyond most savants and no carer reports that the savant has seen such a formula.

Our hypothesis is that repeated scrutiny of calendars results in memory for specific day-date combinations and the discovery of calendrical regularities. These, when combined with ability in mental addition and subtraction, form the basis of calendrical skill. With practice, the skill develops. Consistent with this view, most calendrical savants know calendrical regularities (Cowan, O'Connor, \& Samella, 2001) and savants with greater ranges show ability at mental addition and subtraction (Cowan et al., 2003).

This view, like Ericsson and Faivre's (1988) account, denies the need for exceptional cognitive characteristics apart from obsessive preoccupation, a characteristic of exceptional people and both autistic and non-autistic savants 
(O'Connor \& Hermelin, 1991) and emphasizes the role of practice. However, the evidence is limited. There is no study of unimpaired people with calendrical skills that allows precise comparisons with calendrical savants. The only studies to assess changes over time did not yield evidence of improvement in performance in typically developing or autistic children with calendrical skills (Cowan, Stainthorp, Kapnogianni, \& Anastasiou, 2004; O'Connor \& Hermelin, 1992).

The first study therefore compares calendrical savants with Professor John Conway, a very distinguished mathematician who developed his own method as a teenager and subsequently published a method for others (Berlekamp, Conway, \& Guy, 1982). The second study describes the development of a calendrical savant's ability with practice, but without instruction, to answer questions about the very remote future.

\section{Experiment 1}

Method

\section{Participants}

Professor Conway is the John von Neumann Distinguished Professor of Mathematics at Princeton University. His technique for date questions involves calculating the weekday of the requested year's Doomsday, the 0th March, and using corresponding dates in different months, e.g. 4th April, 6th June, 8th August, 10th October, and 12th December.

Four autistic male adult calendrical savants (GC, DK, DM, MW) were selected for comparison with Professor Conway. Their IQs, calendrical and arithmetical abilities, and onset of calendrical skills were reported in Cowan et al. (2001, 2003) and O'Connor et al. (2000). Neither GC nor DK have shown any 
ability to do mental division of two digit numbers by 4 , as required by the basic formula for calculating dates (Hill, 1978).

\section{Materials and Procedure}

Orally presented dates. Two sets of dates used by O'Connor et al. (2000): a set of 20th century dates with 13 from each of four periods (1912-1919, 19401947, 1968-1976, 1992-1997) and a set of remote future dates, with 5 from each of four periods (12819-12823, 51275-51279, 204380-204383, 819202-819206). Response times were derived from the end of the question to the beginning of the response.

Nomination task. This comprised eight items, two for each of two types of question about years (O'Connor et al., 2000) and four questions about months. There are 14 calendar templates, comprising seven for nonleap years, and seven for leap years. They differ in the day of the week on which a particular date falls. The narrow type of year item, e.g. 'In 1995, 1st March was a Wednesday. Can you tell me any other years with March 1st on a Wednesday?', can only be successfully answered with years from two templates, one for leap years and one for nonleap years. Years from a wider range of templates meet the criteria in the broad type of year item, e.g. 'In 1997, there were five Wednesdays in July. Can you tell me any other years with five Wednesdays in July?'.

The months questions asked for months that begin or end on the same weekday.

\section{Results}

Orally Presented 20th Century Dates

All participants were correct on more than $90 \%$ of trials. Figure 1 shows mean response times for correct trials according to period and calculator. A two - 
way analysis of variance on log times with calculator and period as betweensubjects factors indicated overall differences between calculators, $F(4,233)=$ 52.98, $p<.0005, \eta^{2}=.48$, and periods, $F(3,233)=33.85, p<.0005, \eta^{2}=.30$, and a significant interaction between calculator and periods, $F(12,233)=4.70$, $p<.0005, \eta^{2}=.20$. Post- hoc comparisons $(p<.05)$ indicated DM was faster than the rest. Separate ANOVAs confirmed every savant's latency varied with period but not JC's: GC, $F(3,47)=9.80, p<.0005, \eta^{2}=.39 ; \mathrm{DK}, F(3,47)=$ 18.46, $p<.0005, \eta^{2}=.54 ; \mathrm{DM}, F(3,48)=9.30, p<.0005, \eta^{2}=.37 ; \mathrm{MW}, F(3$, 48) $=9.20, p<.0005, \eta^{2}=.37 ; \mathrm{JC}, F(3,43)=1.08, \mathrm{~ns}, \eta^{2}=.07$.

\section{Remote Future Dates}

JC answered 10 questions. He made one error before requiring the dates be visually presented. Initially he referred to subtracting multiples of 400 , such as 32,000. Then he pointed out that only the last four digits mattered. His response times for correct trials varied between 5.7 and 9.9 seconds $(M=7.3, S D=1.3)$. He correctly answered all three questions asked from each of the two most remote periods, clearly above chance level $(p<.003)$.

Two savants were unsuccessful: DK did not attempt them, and MW performed at chance level (3/20 correct). DM attempted mental calculation of all dates and could be heard to subtract multiples of 700 , consistent with his misconception of the calendar. His answers for all but the remotest period were consistent with this. He took between 4.5 and 21.2 seconds $(\mathrm{M}=11.5, \mathrm{SD}=5.6)$.

GC required all dates to be visually presented and wrote calculations. These exploited the 400-year regularity. He made only two errors, so his success was clearly above chance. He took between 9.5 and 163.3 seconds $(\mathrm{M}=40.5, \mathrm{SD}=$ 40.0). 


\section{Nomination Task}

JC attempted to answer all items by first identifying the weekday for the Doomsday for that year. Having done this, he answered both narrow year items by naming years quite rapidly with occasional errors accompanied by selfcorrections. He gave examples from both templates for each question. Both the leap year and the nonleap year template have the same Doomsday. He said he found the broad year items harder but proceeded to nominate years from some of the templates. The savants varied in the fluency with which they answered the year questions. MW and DM responded quickly as though recalling them. After the first question when he had generated several years, GC explicitly mentioned the 28-year rule to generate other years, said there were many in between but was reluctant to state them. DK required prompting to continue to nominate years.

Nominating months beginning on the same weekday was simple for JC and all the savants apart from DM. GC and MW quickly named months that end on the same weekday but neither DM nor DK succeeded. JC found these items particularly challenging but adapted the Doomsday method and eventually succeeded by going through each month in the year. Table 1 compares his performance with that of the four savants. 


\section{Discussion}

Professor Conway's calendrical skills differed from those of calendrical savants in three ways. He could mentally calculate the answers to date questions from any year in the future, indicating superior ability. He showed no detectable variation in speed with year within the 20th and 21 st centuries, suggesting his method is different. He did not have the same ready access to knowledge of calendrical regularities as some savants but succeeded in working them out. The savants' greater knowledge of calendrical regularities may result from their obsessive preoccupation with calendars.

\section{Experiment 2}

GC's willingness to attempt date questions set in the remote future suggested a study of how his skill might develop with practice. Would his written calculations improve in efficiency? Would he notice the irrelevance of all but the last four digits? Would he progress to mental calculation of remote future dates?

\section{Method}

\section{Materials and Procedure}

Six sets of remote future dates. The first set of 20 dates sampled years from four periods: 912819 -912823, 1204830 -1204833, 1819202 -1819206, and 2051275 -2051279. The second set was randomly generated from a uniform distribution and included 19 dates from the years 190000 to 5000000 . The other four sets were randomly generated from a uniform distribution and each included 20 dates from the years between 250000 and 8000000 . In these sets, only one date had as its final four digits a year between 1700 and 2300 . 
All dates were presented visually and orally over five sessions. GC was congratulated after each correct answer. The only feedback after incorrect answers was to say that his answer differed from the experimenter's. Breaks were offered during sessions. For the last two sets, presented in the final session, GC was asked to answer the questions without writing anything. Sessions were recorded and timings derived from the presentation of the date to GC's writing or announcing of the weekday.

\section{Results}

Table 2 summarizes GC's performance for each set of dates. He became more efficient and remained accurate. He began the first set of dates by writing down several years, each being closer to the 20th century. On the first problem, 21 March 912819, he wrote 8 years $(100019,10019,9619,8019,2019,1991$, 1963, and 1935) before correctly identifying the weekday. Subsequently, he wrote fewer years and only one 20th or 21 st century year.

He began the second set by writing down numerous years, though rarely more than one in the 20th or 21 st centuries, but after the sixth problem wrote down only one or two years for each date before announcing or writing the answer. After the second problem of the third set, he only wrote one or two years and maintained this throughout the fourth set. Across these sets, the number of years he wrote before solution decreased: Kruskal Wallis, $\chi^{2}(3)=34.39, p$ $<.001$. Post hoc comparisons using Mann- Whitney tests $(p<.01)$ indicated the only reliable differences were between the first and subsequent sets. In no set was number of years written related to remoteness of year: all $r_{s} \mathrm{~s}$ between - .20 and .25 . 
As Table 2 also shows, response time varied considerably within sets. Although GC would say some years were easier than others, he was not able to say why. Inspection of his written steps suggested he first subtracted multiples of 400 from the target year to find a corresponding year between 1800 and 2200. If this resulted in a year in the 20th or 21 st centuries, he would then typically announce the weekday. If it resulted in a year outside them, he added or subtracted until he had reached a calendrically equivalent year in these centuries.

This suggested examining the relations between his response times and the absolute difference between the year 2000 and the corresponding year, e.g. if the target year was 4327144, the corresponding year is 1944 and the absolute difference is 56 . His log response times for the third and subsequent sets of dates were significantly related to this variable ( $r$ s ranged between .54 and .82 , all $p$ s $<.05)$. In contrast there was no relation at all between log response time and year given or last four digits of year in any date set (all $r$ s ranged between - -.47 and .31, all $n s)$.

He became faster across sets according to a one-way ANOVA of log response times, $F(5,105)=7.57, p<.0005, \eta^{2}=.27$. Ryan-Einot-GabrielWelsch Q post hoc comparisons $(p<.05)$ indicated response times for the first two sets were longer than the rest, which did not differ.

\section{Discussion}

GC progressed from using cumbersome and time-consuming written methods to answering remote future date questions by purely mental calculation. Without prompting, he developed a method of converting remote future dates into those from current or adjacent centuries. GC did not explicitly state that only the last four digits mattered but would appear to have discovered this towards the 
end of the first set of dates when he was only writing down four digit years. He did not always exploit this as his solutions to the first dates in the second set indicate. Analogously, when young children start using new and more sophisticated strategies in arithmetic they do not immediately abandon existing strategies (Siegler, 1996).

Some dates in later sets took him much longer to answer than others. This appeared to be due to the proximity to 2000 of the corresponding year obtained by subtracting multiples of 400 . The variation in his response time for remote dates resembled his variation for 20th century dates.

Comparing GC to Professor Conway indicates two differences and one similarity. First Professor Conway was much faster to discover the irrelevance of all but the last four digits. This is likely to reflect Professor Conway's superior intelligence and awareness of numerical structure. Second, GC shows variation in response time with remote years similar to that for nearer years. Professor Conway shows no such variation. Both discovered ways of extending their methods to remote future dates but their methods are different and Professor Conway was much more efficient. Finally, both required the dates to be externally represented, indicating that answering remote future date questions involved working memory resources, as might be expected if calculation is an important component of both their methods.

\section{General Discussion}

These studies aimed to clarify the exceptionality of the skills of calendrical savants and the role of practice in the development of calendrical skill. Experiment 1 compared autistic calendrical savants with a mathematician. The mathematician was not as fast as one savant and he had to work out some 
answers to calendrical questions but he demonstrated his superiority in becoming able to answer any question about remote future dates by mental calculation after little experience.

Experiment 2 examined a savant's development of the ability to answer questions about dates in the remote future. It showed that he gradually progressed in efficiency in calculation with the aid of paper and pencil until he could dispense with these.

The results are consistent with our hypothesis about the development of calendrical skills by savants in claiming that these develop with practice and require no exceptional cognitive characteristics. Calendrical calculation is not difficult to acquire, as its emergence in 5- and 6-year-old typically developing boys suggests (Cowan et al., 2004). Calendrical savants have developed their skills beyond the levels achieved by the boys. This may be due to the social reinforcement savants receive by demonstrating their skills. In contrast, typically developing children receive praise for more conventional achievements.

Our account does not draw on features of autistic cognition, such as weak central coherence (Frith, 1989; Happé, 1999; Heaton, Hermelin, \& Pring, 1998) or enhanced perceptual functioning (Mottron \& Burack, 2001), that might explain the development of musical and artistic savant skills. There are several reasons for this. Calendrical savants do not show the profile characteristic of weak central coherence (O'Connor et al., 2000). General intelligence is more relevant to calendrical calculation and other arithmetical savant skills (Anderson, 1992; Hermelin \& O'Connor, 1986; O'Connor et al., 2000) than artistic abilities (O'Connor \& Hermelin, 1987a, 1987b, 1990). Also, calendrical calculation appears not to be so disproportionately represented in autistic samples as musical 
and artistic ability (Saloviita, Ruusila, \& Ruusila, 2000). So we question the relevance of autism to calendrical calculation, apart from the tendency to obsessive preoccupations shown by both autistic and nonautistic savants (O’Connor \& Hermelin, 1991).

Finally, we do not claim that calendrical savants are neurally abnormal. Although some propose that all savants are severely brain impaired and that this enables them to access information that is in us all (Snyder \& Mitchell, 1999), the only skills reported to result from brain damage (Miller et al., 1998) or repetitive transcranial magnetic stimulation (Snyder et al., 2003) are artistic. Whether calendrical savants show unusual brain characteristics or show activity in brain regions different from those involved in normal arithmetical processing when calculating dates remains to be seen. 


\section{Acknowledgement}

The sample of calendrical savants came from the pool built up by Dr Neil O'Connor and Professor Beate Hermelin. We thank them, Professor Conway, and the savants for their co-operation.

Correspondence and requests for reprints should be addressed to Dr Richard Cowan, Psychology and Human Development, Institute of Education University of London, 20 Bedford Way, London WC1H 0AL, UK. Electronic mail may be sent via Internet to r.cowan@ioe.ac.uk. 


\section{References}

Anderson, M. (1992). Intelligence and development: A cognitive theory. Oxford: Blackwell.

Berlekamp, E. R., Conway, J. H., \& Guy, R. K. (1982). Winning ways (Vol. 2). New York: Academic Press.

Cowan, R., O'Connor, N., \& Samella, K. (2001). Why and how people of limited intelligence become calendrical calculators. Infancia y Aprendizaje, 93, 5365.

Cowan, R., O'Connor, N., \& Samella, K. (2003). The skills and methods of calendrical savants. Intelligence, 31, 51-65.

Cowan, R., Stainthorp, R., Kapnogianni, S., \& Anastasiou, M. (2004). The development of calendrical skills. Cognitive Development, 19, 169-178.

Ericsson, K. A., \& Faivre, I. A. (1988). What's exceptional about exceptional abilities? In L. K. Obler \& D. Fein (Eds.), The exceptional brain: Neuropsychology of talent and special abilities (pp. 436-473). New York: Guilford Press.

Frith, U. (1989). Autism: Explaining the enigma. Oxford: Blackwell.

Happé, F. (1999). Autism: cognitive deficit or cognitive style? Trends in Cognitive Science, 3, 216-222.

Heaton, P., Hermelin, B., \& Pring, L. (1998). Autism and pitch processing: A precursor for savant musical ability? Music Perception, 15, 291-305.

Hermelin, B., \& O'Connor, N. (1986). Idiot savant calendrical calculators: Rules and regularities. Psychological Medicine, 16, 885-893. 
Hill, A. L. (1978). Savants: Mentally retarded individuals with special skills. In N. R. Ellis (Ed.), International Review of Research in Mental Retardation (Vol. 9, pp. 277-298). London: Academic Press.

Miller, B. L., Cummings, J., Mishkin, F., Boone, K., Prince, F., Ponton, M., \& Cotman, C. (1998). Emergence of artistic talent in frontotemporal dementia. Neurology, 51, 978-982.

Mottron, L., \& Burack, J. A. (2001). Enhanced perceptual functioning in the development of autism. In J. A. Burack, T. Charman, N. Yirmiya , \& P. R. Zelazo (Eds.), The development of autism: Perspectives from theory and research (pp. 131-148). Hillsdale, NJ: Lawrence Erlbaum Associates.

O'Connor, N., Cowan, R., \& Samella, K. (2000). Calendrical calculation and intelligence. Intelligence, 28, 31-48.

O'Connor, N., \& Hermelin, B. (1984). Idiot savant calendrical calculators: Maths or memory? Psychological Medicine, 14, 801-806.

O'Connor, N., \& Hermelin, B. (1987a). Visual and graphic abilities of the idiot savant artist. Psychological Medicine, 17, 79-90.

O'Connor, N., \& Hermelin, B. (1987b). Visual memory and motor programmes: Their use by idiot-savant artists and controls. British Journal of Psychology, 78, 307-323.

O'Connor, N., \& Hermelin, B. (1990). The recognition failure and graphic success of idiot-savant artists. Journal of Child Psychology and Psychiatry, 31, 203-215.

O'Connor, N., \& Hermelin, B. (1991). Talents and preoccupations in idiotsavants. Psychological Medicine, 21, 959-964. 
O'Connor, N., \& Hermelin, B. (1992). Do young calendrical calculators improve with age? Journal of Child Psychology and Psychiatry, 33, 907-912.

Saloviita, T., Ruusila, L., \& Ruusila, U. (2000). Incidence of savant syndrome in Finland. Perceptual and Motor Skills, 91, 120-122.

Siegler, R. S. (1996). Emerging minds: The process of change in children's thinking. Oxford: Oxford University Press.

Snyder, A. W., \& Mitchell, D. J. (1999). Is integer arithmetic fundamental to mental processing?: the mind's secret arithmetic. Proceedings of the Royal Society London B, 266, 587-592.

Snyder, A. W., Mulcahy, E., Taylor, J. L., Mitchell, D. J., Sachdev, P., \& Gandevia, S. C. (2003). Savant-like skills exposed in normal people by suppressing the left fronto-temporal lobe. Journal of Integrative Neuroscience, 2, 149-158.

Young, R. L., \& Nettelbeck, T. (1994). The "intelligence" of calendrical calculators. American Journal on Mental Retardation, 99, 186-200. 
Exceptionality and practice 18

Figure Caption

Figure 1. Mean response times for orally presented dates according to period and calculator. Data from calendrical savants were previously summarized in Cowan et al. (2003). Copyright 2003 by Elsevier. Reprinted with permission. 
Table 1

Nomination Task Performance in Experiment 1

\begin{tabular}{|c|c|c|c|c|c|}
\hline & $\mathrm{JC}$ & $\mathrm{GC}$ & DK & $\mathrm{DM}$ & MW \\
\hline \multicolumn{6}{|l|}{ Narrow years items } \\
\hline Number of years & 20 & 28 & 28 & 17 & 51 \\
\hline Accuracy $(\%)$ & 80 & 100 & 100 & 100 & 96 \\
\hline Number of year & 4 & 3 & 4 & 4 & 4 \\
\hline \multicolumn{6}{|l|}{ templates (out of 4) } \\
\hline \multicolumn{6}{|l|}{ Broad years items } \\
\hline Number of years & 16 & 17 & 7 & 5 & 37 \\
\hline Accuracy $(\%)$ & 81 & 100 & 100 & 20 & 97 \\
\hline Number of year & 5 & 8 & 4 & 1 & 4 \\
\hline \multicolumn{6}{|l|}{ templates (out of 10) } \\
\hline \multicolumn{6}{|l|}{ Months items } \\
\hline Same start (out of 2) & 2 & 2 & 2 & 1 & 2 \\
\hline Same finish (out of 2) & 2 & 2 & 0 & 0 & 2 \\
\hline
\end{tabular}

Data from calendrical savants on years items were previously reported in O'Connor et al. (2000). Copyright 2000 by Elsevier. Reprinted with permission. 
Table 2

GC's Accuracies, Times, and Number of Years Written Down for Remote Future

Dates in Experiment 2

\begin{tabular}{lccccc}
\hline Set & Accuracy $(\%)$ & \multicolumn{2}{c}{ Response time (s) } & \multicolumn{3}{c}{ Years } \\
& & M & SD & M & SD \\
\hline First & 80 & 46.4 & 48.8 & 4.1 & 1.4 \\
Second & 100 & 57.1 & 73.0 & 2.9 & 3.4 \\
Third & 100 & 19.2 & 17.9 & 1.3 & 0.8 \\
Fourth & 95 & 14.1 & 10.8 & 1.3 & 0.5 \\
Fifth & 100 & 13.1 & 11.0 & $-{ }^{\mathrm{a}}$ & \\
Sixth & 85 & 19.9 & 15.0 & $-{ }^{\mathrm{a}}$ & \\
\hline
\end{tabular}

${ }^{a} \mathrm{GC}$ answered date questions in these sets without writing any years. 